mann reaction was negative. On the 15th signs of cedema of the lungs were evident, and the patient died on the 16th. With the exception of the evening pyrexia on the 8 th the temperature chart showed no departure from the norma.

Necropsy (28 hours after death). - The body was that of a fairly well-nourished youth. The parotid regions showed slight swelling bilaterally. There was extensive marginal ulceration of the gums. The scrotum contained one testis. There was no phimosis.

Head and neck.-No macroscopic abnormalities of brain or meninges; a bilateral suppurative parotitis, with abscess formation in the left gland ; larynx, trachea, and osophagus were normal.

Thorax.-Pleural and pericardial cavities normal; lungs bulky, engorged, and very cdematous; heart showed moderate hypertrophy of left ventricle; cardiac valves all healthy; cardiac musculature appeared in good condition.

Abdomen.-Liver and spleen normai; left testis small and atrophic and lying in left iliac fossa: intestines empty and collapsed. On inspection of renal regions kidneys could not be located ; adrenals, however, in usual position ; kidneys found to be lying on alæ of sacrum, each organ between psoas magnus and vertebral column, and partly in abdomen and partly in pelvis. Psoas muscles did not arise from the vertebral column lower than the third lumbar vertebra, and in order to accommodate the ectopic kidneys were placed much further from the mid-line than is usual. Ureters short, situate entirely within cavity of true pelvis and markedly dilated, measuring about $3 \mathrm{~cm}$. in circumference. Bladder distended and hypertrophied, containing about $18 \mathrm{oz}$. of clear urine with a high colour; no calculi. Dissection of prostatic urethra showed normal verumontanum without any enlargement of prostate. Kidneys small, showing marked lobulation; on section they were of a pale brown colour. No differentiation between cortex and medulla visible : the capsule was firmly adherent, leaving when stripped a rough pitted surface. As a whole the organ felt very firm and fibrous. Neither hydronephrosis nor dilatation of the pelvis.

Microscopical examination of the kidneys revealed a very advanced degree of chronic interstitial nephritis, the organs being converted practically into a mass of fibrous tissue. The penile urethra was not examined directly, but as micturition for the frethra was not examined directly, but as micturition for the exclude the existence of "valves" of the urethra. There was, as stated, no phimosis, and the easy passage of a soft rubber catheter would negative the suggestion of the existence of a catheter

Hypertrophy of the bladder with dilatation of the ureters consequent upon obstruction of the urethra is well known, but several instances have been recorded of this combination without any such obstruction having been found. ${ }^{2}$ A further item of interest in this case is the ectopic position of the kidneys. It would also appear to be distinctly unusual for dilatation of the ureters to occur to a marked degree without a corresponding involvement of the kidney.

\section{A CIGARETTE-HOLDER IN THE LARYNX.}

\section{By N. Hay Bolton, M.D. Edin.}

THE following case, which was treated at the Shantung-road Hospital, Shanghai, is sufficiently uncommon to be worthy of record.

Loo Va Le, a Chinese boy, aged 10, was admitted to hospital on Jan. 10th with the history that four days previously he had been sucking a Chinese wire cigarette-holder and had suddenly swallowed" it.

Examination.-The patient was somewhat breathless and cyanosed; his temperature was $1024^{\circ} \mathrm{F}$. and he could only speak in a whisper. With the laryngeal mirror he was found to have an infantile type of epiglottis, but it was just possible to see the upper end of the cigarette-holder, apparently tightly gripped between the false cords; the lumen of its tube evidently constituted all the available space through which he could breathe. The upper

operation. - I thought it might be possible to extract the foreign body from above, and so (having put the tracheotomy instruments on to boil) proceeded to cocainise the throat; but the patient on to boil) proceeded to cocainise the throat; but the patient tomy was performed under chloroform anzesthesia. In opening the tomy was performed under chloroform anæesthesia. In opening the trachea I cut right down on the cigarette-holder, and by extending the incision downwards was able to get hold of the lower end and pull it gently down and out through the wound. I put the tracheofomy thabe in place, but at this point the patient stopped breathing and we had an anxious three or four minutes performing artificial respiration until normal breathing recommenced. I left the racheotomy tube in place for 48 hours in order to give time for the traumatic laryngitis to subside, and then withdrew it. The sixtb day after operation; the neck wound healed up perfectly and there were no chest symptoms.

After about 10 days the patient's voice began to acquire tone, and on leaving hospital 24 days after operation he could speak with a fairly clear but weak voice ; the true cords, however, were still thickened and inflamed.

The cigarette-holder was $2 \frac{1}{2}$ in. long, $\frac{3}{8}$ in. in diameter at the wider end, and $\frac{1}{1}$ in. in diameter at the narrow end ; the lumen at the narrow end was barely $\frac{1}{8}$ in. in diameter.

2 C. R. Box: Proc. Royal Society of Medicine February, 1909.

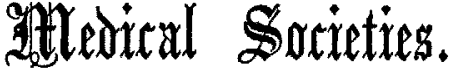

\author{
ROYAL SOCIETY OF MEDICINE.
}

\section{SECTION OF SURGERY : SUBSECTION OF ORTHOP AEDICS.}

EXHIBITION OF CASES AND SPECIMENS.

A MEETING of this subsection of the Royal Society of Medicine was held on March 1st, Mr. E. Laming EVANs, the President, being in the chair.

Recurrent or Habitual Dislocation of the Shoulder-joint.

The PRESIDENT, in opening a discussion on this subject defined the condition as one in which a joint after dislocation has occurred and has been reduced and has remained reduced, offers a subnormal resistance to redislocation, and, in fact, suffers repeated dislocations by slight force. The shoulder is by far the most common joint affected. This is accounted for by the fact that 50 per cent. of all dislocations occur in the shoulder, by the reduction by unskilled hands, by defective after-treatment, and by the normal anatomical structure of the joint and the damage inflicted by the initial injury. The pathological lesions were discussed in detail.

The following methods of treatment have been employed: (1) Palliative, by the use of appliances to limit the joint movements. (2) Physiological, by increasing the tone of muscle, tendon, and ligament. (3) By reefing operations upon the capsule : $(a)$ plication (b) excision and overlapping. (4) By repair of ruptured tendons and musculo-tendinous insertions. (5) By muscle transplantation. A fair trial of mechanical support and physiological toning should be tried first, as they have cured cases. Reefing operations had been followed by many successes and not a few failures. Muscle transplantation has been performed by detach. ing the posterior fibres of the deltoid, passing them forwards inside the neck of the humerus and fixing them in front. Opinions differ as to whether the graft retains its contractile power, or undergoes fibrous degeneration.

He showed the following case treated by this (Clairmont's) muscle transplantation operation :-

Major - aged 41 years. Left shoulder dislocated at football in 1899, and redislocated 19 times since. When seen in 1920 even sneezing would produce dislocation, which was always attended by much pain and required surgical assist ance for reduction. The dislocation was subcoracoid. Clairmont's operation performed in August, 1920. The "quadrilateral space" is defined through an anterior incision, some fibres of the pectoral major and latissimus dorsi being divided. Through a posterior incision a strip of the deltoid, with its nerve and blood-supply intact, is separated and its insertion divided. Not more than a quarter of the deltoid should be used. The free end of the flap is passed forwards through the quadrilateral space and sutured to the anterior fibres of the deltoid in front. The tension on the graft must be sufficient, but not excessive. The shoulder was fixed for six weeks when active and passive movements were begun. The result has been satisfactory so far. He can go into a practice scrum and demonstrate to his pupils how to get the ball.

Mr. 'T. H. OPENSHAW showed a man, the subject of epilepsy, on whom he had operated first 15 years ago. The right shoulder had been "out" 50 times and the left 35 times. Dealing with the right shoulder, he tried injections of irritants-e.g., iodine, carbolic, \&c.on four occasions; he cut the pectoralis major and teres major, he plicated the capsule, he performed an arthrodesis, all of which gave only temporary, if any, benefit. Finally, he cut the subscapularis and this cured him. On the left he did an arthrodesis and later cut the sub scapularis. The result was spoilt by a fall, which produced a traumatic dislocation, and the recurrent trouble returned; he had the shoulder out three times in ten days. A second arthrodesis cured him. He said he had operated on ten cases of this sort, doing nothing but divide the subscapularis, and all had been successful, and he knew of others treated in a similar manner with equal success. 